\title{
A Monte Carlo Comparison of Regression Estimators When the Error Distribution is Long- Tailed Symmetric
}

Oya Can Mutan

ODTU, Turkey, oya.canmutan@spk.gov.tr

Birdal Şenoğlu

Ankara University, Turkey, senoglu@science.ankara.edu.tr

Follow this and additional works at: http://digitalcommons.wayne.edu/jmasm

Part of the Applied Statistics Commons, Social and Behavioral Sciences Commons, and the Statistical Theory Commons

\section{Recommended Citation}

Mutan, Oya Can and Şenoğlu, Birdal (2009) "A Monte Carlo Comparison of Regression Estimators When the Error Distribution is Long-Tailed Symmetric," Journal of Modern Applied Statistical Methods: Vol. 8 : Iss. 1, Article 14.

DOI: $10.22237 /$ jmasm/1241136780

Available at: http://digitalcommons.wayne.edu/jmasm/vol8/iss1/14 


\section{A Monte Carlo Comparison of Regression Estimators When the Error Distribution is Long-Tailed Symmetric}

\author{
Oya Can Mutan \\ ODTU, Turkey
}

\author{
Birdal Şenoğlu \\ Ankara University, Turkey
}

The performances of the ordinary least squares (OLS), modified maximum likelihood (MML), least absolute deviations (LAD), Winsorized least squares (WIN), trimmed least squares (TLS), Theil's (Theil) and weighted Theil's (Weighted Theil) estimators are compared under the simple linear regression model in terms of their bias and efficiency when the distribution of error terms is long-tailed symmetric.

Key words: Long-tailed symmetric, ordinary least squares, modified maximum likelihood, least absolute deviations, Winsorized least squares, trimmed least squares, Theil's method, Weighted Theil's method.

\section{Introduction}

Consider the simple linear regression model:

$$
y_{i}=\beta_{0}+\beta_{1} x_{i}+e_{i},
$$

where $(i=1,2, \ldots, n), y_{i}$ is the response variable, $x_{i}$ is a nonstochastic explanatory variable and $\beta_{0}$ and $\beta_{1}$ are the unknown parameters. Traditionally, error terms $e_{i}$ $(1 \leq i \leq n)$ are assumed to be independently and identically distributed (iid) normal $N\left(0, \sigma^{2}\right)$ and the regression coefficients $\beta_{0}$ and $\beta_{1}$ are estimated by using the OLS estimators given by

Oya Can Mutan is a Statistician in the Capital Markets Board of Turkey. She received her B.S. (statistics), M.S. (statistics, economics) and Ph.D. (statistics) degrees from Middle East Technical University in Turkey. Email: oya.canmutan@spk.gov.tr. Birdal Şenoğlu is an Associate Professor in the Department of Statistics at Ankara University, Turkey. He received his B.S. and Ph.D. degrees (statistics) from Middle East Technical University in Turkey and his M.S. (statistics) degree from Iowa State University, USA. Email: senoglu@science.ankara.edu.tr.

$$
\hat{\beta}_{0}=\bar{y}-\hat{\beta}_{1} \bar{x}
$$

and

$$
\hat{\beta}_{1}=\sum_{i=1}^{n}\left(x_{i}-\bar{x}\right) y_{i} / \sum_{i=1}^{n}\left(x_{i}-\bar{x}\right)^{2}
$$

respectively.

The OLS estimators are optimal only if the error distribution is normal. However, in most real life applications, nonnormal distributions are more prevalent; see, Pearson (1932), Geary (1947), Huber (1981), Şenoğlu (2005) and Şenoğlu (2007). Additionally, the occurrence of outliers in a data set is another indication of nonnormality. Due to these weaknesses of the OLS estimators, statisticians prefer to use the alternative regression estimators which are more efficient and robust under nonnormality

However, the choice of which method to use is not defined clearly for different types of error distributions. In the literature, there exists a very limited number of researches comparing alternative regression methods, see Tam (1996) and Nevitt and Tam (1998). In this study, our main concern is to identify the most efficient method when the error distribution is long-tailed symmetric and also to see the effect of nonnormality on the efficiencies and robustness of the regression estimators. 


\section{LONG- TAILED SYMMETRIC DISTRIBUTION REGRESSION ESTIMATORS}

Long-tailed Symmetric (LTS) Distribution

The LTS distribution has the probability density function:

$$
\begin{gathered}
\operatorname{LTS}(p, \sigma): f(e) \propto \frac{1}{\sigma}\left\{1+\frac{e^{2}}{k \sigma^{2}}\right\}^{-p}, \\
-\infty<e<\infty
\end{gathered}
$$

with $k=2 p-3$ and $p \geq 2$. The mean and variance of the random variable $e$ is 0 and $\sigma^{2}$, respectively. See also the following table for the Pearson coefficient of kurtosis, i.e., $\beta_{2}=\mu_{4} / \mu_{2}^{2}$ of the $\operatorname{LTS}(p, \sigma)$ distribution:

$$
\begin{array}{lccccc}
p= & 2.5 & 3.5 & 5.0 & 10 & \infty \\
\beta_{2}= & \infty & 9 & 4.2 & 3.4 & 3.0
\end{array}
$$

This reduces to the normal distribution when $p$ is equal to $\infty$.

Methodology

OLS is the most popular method for estimating the parameters of the simple linear regression model. This is partly due to the relative simplicity of its computations. However, the OLS method is very sensitive to outliers and to nonnormality. To remedy these problems, alternative regression methods have been developed that are not sensitive to the violations of the assumptions of the simple linear regression model. The only disadvantage of these alternative methods is their computational difficulty. Today, however, computational difficulties are unimportant issue because of the improvements in computer technology (see Birkes \& Dodge, 1993; Rousseeuw \& Leroy, 1987).

The Modified Maximum Likelihood Method

The maximum likelihood (ML) estimators are the solutions of the equations

$$
\begin{aligned}
& \partial \ln L / \partial \beta_{0}=0, \\
& \partial \ln L / \partial \beta_{1}=0,
\end{aligned}
$$

$$
\partial \ln L / \partial \sigma=0
$$

These equations do not have explicit solutions. Tiku, et al. (2001) express likelihood equations in terms of order statistics (for a given $\beta_{1}$ ), since complete sums are invariant to ordering.

$$
z_{(i)}=\frac{y_{[i]}-\beta_{0}-\beta_{1} x_{[i]}}{\sigma},(1 \leq i \leq n)
$$

where $\left(y_{[i]}, x_{[i]}\right)$ is that pair of observations which correspond to $z_{(i)}(1 \leq i \leq n) ;\left(y_{[i]}, x_{[i]}\right)$ are called the concomitants of $z_{(i)}$. They linearize the intractable functions $g\left(z_{(i)}\right)=z_{(i)} /\left\{1+(1 / k) z_{(i)}^{2}\right\}$ by using the first two terms of a Taylor series expansion by using the following linear approximation

$$
g\left(z_{(i)}\right) \cong \alpha_{i}+\beta_{i} z_{(i)}, 1 \leq i \leq n
$$

where

$$
\alpha_{i}=\frac{(2 / k) t_{(i)}^{3}}{\left(1+(1 / k) t_{(i)}^{2}\right)^{2}}
$$

and

$$
\beta_{i}=\frac{1-(1 / k) t_{(i)}^{2}}{\left(1+(1 / k) t_{(i)}^{2}\right)^{2}}
$$

$t_{(i)}$ 's $(i=1,2, \ldots ., n)$ are the expected values of the order statistics $z_{(i)}$, i. e., $t_{(i)}=E\left(z_{(i)}\right)$. Incorporating (4) in (3), results in modified likelihood equations:

and

$$
\begin{aligned}
& \partial \ln L^{*} / \partial \beta_{0}=0, \\
& \partial \ln L^{*} / \partial \beta_{1}=0,
\end{aligned}
$$

$$
\partial \ln L^{*} / \partial \sigma=0
$$

These equations have explicit solutions called as MML estimators:

$$
\hat{\beta}_{0}=\bar{y}_{[.]}-\hat{\beta}_{1} \bar{x}_{[.]}
$$




\section{MUTAN \& ŞENOĞLU}

$$
\begin{gathered}
\hat{\beta}_{1}=K+D \hat{\sigma} \\
\hat{\sigma}=\frac{B+\sqrt{B^{2}+4 n C}}{2 \sqrt{n(n-2)}}
\end{gathered}
$$

where

$$
\begin{gathered}
\bar{y}_{[.]}=\sum_{i=1}^{n} \beta_{i} y_{[i]} / m, \bar{x}_{[.]}=\sum_{i=1}^{n} \beta_{i} x_{[i]} / m, \\
\left(m=\sum_{i=1}^{n} \beta_{i}\right), \\
K=\sum_{i=1}^{n} \beta_{i}\left(x_{[i]}-\bar{x}_{[.]}\right) y_{[i]} / \sum_{i=1}^{n} \beta_{i}\left(x_{[i]}-\bar{x}_{[.]}\right)^{2}, \\
D=\sum_{i=1}^{n} \alpha_{i} x_{[i]} / \sum_{i=1}^{n} \beta_{i}\left(x_{[i]}-\bar{x}_{[.]}\right)^{2}, \\
B=(2 p / k) \sum_{i=1}^{n} \alpha_{i}\left\{y_{[i]}-\bar{y}_{[.]}-K\left(x_{[i]}-\bar{x}_{[.]}\right)\right\}
\end{gathered}
$$

and

$$
C=(2 p / k) \sum_{i=1}^{n} \beta_{i}\left\{y_{[i]}-\bar{y}_{[\cdot]}-K\left(x_{[i]}-\bar{x}_{[\cdot]}\right)\right\}^{2} .
$$

Least Absolute Deviations (LAD)

The LAD regression method was developed by Roger Joseph Boscovich in 1757, see Birkes and Dodge (1993). The LAD estimators of regression coefficients, $\beta_{0}$ and $\beta_{1}$, are found by minimizing the function:

$$
F=\sum_{i=1}^{n}\left|y_{i}-\left(\beta_{0}+\beta_{1} x_{i}\right)\right| \text {. }
$$

Although the logic behind LAD is not more difficult than the concept of OLS, calculation of the LAD estimates is more troublesome. An algorithmic method is used for the calculation of the $\mathrm{LAD}$ estimates $\hat{\beta}_{0}$ and $\hat{\beta}_{1}$, since there are no exact formulas.

This algorithm starts with one of the data points $(x, y)$, say $\left(x_{1}, y_{1}\right)$, and tries to find the best line passing through it. The line passing through $\left(x_{1}, y_{1}\right)$ also passes through another data point denoted by $\left(x_{2}, y_{2}\right)$. Next we find the best line passing through $\left(x_{2}, y_{2}\right)$. As the algorithm continues, we obtain increasingly better lines and finally the most recent line obtained will be the same as the previous line. This line is the best line and it is called as LAD regression line, see Birkes and Dodge (1993) for more detailed information.

\section{Winsorized Least Squares}

The WLS which is an iterative method is another alternative to OLS method; see Yale and Forsythe (1976). Smoothing techniques based on the OLS estimation are applied to reduce the effect of the outliers in the sample. The basic idea is to replace the most extreme residual with the next closest residual in the sample in an iterative way. In the literature, the studies show that Winsorization does not worsen a good linear relationship on non-contaminated data. On the contrary, it improves the estimates $\hat{\beta}_{0}$ and $\hat{\beta}_{1}$, when the sample is contaminated with outliers.

\section{Trimmed Least Squares}

The fourth method is the TLS introduced by Rousseeuw in 1984. The TLS estimation procedure is similar to the OLS estimation, but in TLS procedure, the fit is not so much affected from the outliers, because the data points corresponding to a specified percentage of the highest residuals based on an initial OLS estimation are removed. The OLS estimates of slope and intercept for the remaining data are called TLS estimates, see Rousseeuw and Leroy (1987) and Nevitt and Tam (1998). The aim is to minimize

$$
\sum_{i=1}^{h}\left(y_{i}-\beta_{0}-\beta_{1} x_{i}\right)^{2}
$$

As it is seen in equation (6), rather than smoothing the data as in Winsorized regression, the outlying cases are deleted, therefore the $n-h$ observations do not affect the estimators.

Theil's Method

Theil's nonparametric regression method using the median as robust measures (see Theil, 1950) is presented. In Theil's 


\section{LONG- TAILED SYMMETRIC DISTRIBUTION REGRESSION ESTIMATORS}

method, the only assumption is that the error terms are identically and independently distributed (i.i.d); this is different than the robust methods.

Sprent (1993) stated that for a simple linear regression model to obtain the slope of a line that fits the data points, the set of all slopes $b_{i j}=\frac{y_{j}-y_{i}}{x_{j}-x_{i}}$ of lines joining pairs of data points $\left(x_{i}, y_{i}\right),\left(x_{j}, y_{j}\right), x_{j} \neq x_{i}$, for $1 \leq i<j \leq n$ should be calculated.

Hussain and Sprent (1983) say that no generality is lost if $1 \leq i<j \leq n$ is taken, assuming that the $x_{i}$ 's are arranged in ascending order (note that $b_{i j}=b_{j i}$ ). According to these results the Theil's slope estimator is:

$$
\hat{\beta}_{1}=\operatorname{med}\left\{b_{i j} \mid x_{j} \neq x_{i}\right\}
$$

where $x_{1} \leq x_{2} \leq \ldots \leq x_{n}$.

It is known that median estimators are less affected from the outlying values in the data set as compared to the mean estimators, i.e., they are resistant estimators. The corresponding intercept term is defined as the median of the $y_{i}-\hat{\beta}_{1} x_{i}$ terms (see Birkes \& Dodge, 1993).

\section{Weighted Theil's Method}

A modified version of the Theil's method is called a Weighted Theil's Regression Method. In this method, different than the Theil's original method, each of the pairwise slopes are weighted using a weighting scheme. The weighted Theil slope estimator for the $n$ observations in the sample data is the weighted median of these $b_{i j}$ 's. $w_{i j}$, as the weighting procedure, can be taken as

$$
x_{j}-x_{i}, j-i \text { or }\left|x_{j}-x_{i}\right|,
$$

see, for example Jaeckel (1972) and Scholz [16] and Birkes and Dodge (1993). In this study, the weights $w_{i j}=\frac{\left(x_{i}-x_{j}\right)^{2}}{\sum\left(x_{i}-x_{j}\right)^{2}}$ were used to calculate the slope estimator $\hat{\beta}_{1}=\sum w_{i j} b_{i j}$. The intercept estimator is calculated in a similar fashion as in Theil's original method.

\section{Results}

The design points $x_{i} \quad(1 \leq i \leq n)$ follow an equally spaced, sequential additive series $\left(x_{i}=1\right.$, $2, \ldots, n)$ (see Hussain \& Sprent, 1983) and are common to all random samples $\left(y_{1}, y_{2}, \ldots . ., y_{n}\right)$ for the $N=[100,000 / n]$ (integer) Monte Carlo runs. The error terms, $e_{i}$, are generated from the long-tailed symmetric distribution given above, and $\beta_{0}, \beta_{1}$ and $\sigma$ are taken to be 0,1 ( 1 in the remainder of this article) without loss of generality. The simulated means, variances and mean square errors (MSE) of the estimators are computed for some selected values of $p$ (2.0, 2.5, 3.0, 3.5 and 5.0) and the results are given in Table 1.

From the simulation results presented in Table 1, all of the methods of estimation produced negligible bias therefore comparisons may be made in terms of MSE for both $\hat{\beta}_{0}$ and $\hat{\beta}_{1}$. In view of MSE, the following conclusions are put forth for the intercept estimator $\hat{\beta}_{0}$ :

- WIN20 and WIN10 outperformed other estimators at all sample sizes for $p<3$. For moderate $(n=20)$ and large sample sizes $(n=50)$ they had the smallest MSE when $p$ $=3.0$. For values of the shape parameter $p$ greater than 3, WIN20 and WIN10 were the preferred estimators for large sample sizes $(n=50)$.

- The performance of the MML is best for small sample sizes $(n=10)$ when $p=3$. When $p=3.5$ and 5, the highest performance was achieved by MML for small $(n=10)$ and moderate $(n=20)$ samples.

- LAD and TLS performed poorly at all sample sizes for all values of the shape parameter $p$. As expected, the performance of OLS was the worst for $p=2.5$, however, it consistently increased with the value of 


\section{MUTAN \& ȘENOĞLU}

Table 1: Means, Variances and MSE's for the estimators $\hat{\beta}_{0}$ and $\hat{\beta}_{1}, n=10$

\begin{tabular}{|c|c|c|c|c|c|c|}
\hline \multirow[b]{2}{*}{ Method } & \multicolumn{3}{|c|}{$\hat{\beta}_{0}$} & \multicolumn{3}{|c|}{$\hat{\beta}_{1}$} \\
\hline & Mean & Variance & MSE & Mean & Variance & MSE \\
\hline \multicolumn{7}{|c|}{$\mathrm{p}=2.0$} \\
\hline$\overline{\mathrm{OLS}}$ & 0.003516 & 0.442733 & 0.442745 & 0.998563 & 0.011514 & 0.011516 \\
\hline MML & 0.004207 & 0.341639 & 0.341656 & 0.998604 & 0.009006 & 0.009008 \\
\hline LAD & -0.002318 & 0.362488 & 0.362493 & 0.999963 & 0.009799 & 0.009799 \\
\hline WIN10 & 0.000232 & 0.361181 & 0.361181 & 0.999536 & 0.009411 & 0.009411 \\
\hline WIN20 & 0.001934 & 0.300163 & 0.300167 & 0.999102 & 0.007824 & 0.007825 \\
\hline TLS & 0.006592 & 0.329992 & 0.330035 & 0.998576 & 0.008706 & 0.008708 \\
\hline Theil & 0.000764 & 0.314738 & 0.314738 & 0.999397 & 0.008095 & 0.008096 \\
\hline Wtd.Theil & 0.001506 & 0.312057 & 0.312059 & 0.999328 & 0.008060 & 0.008060 \\
\hline \multicolumn{7}{|c|}{$\mathrm{P}=2.5$} \\
\hline$\overline{\mathrm{OLS}}$ & -0.003356 & 0.461119 & 0.461130 & 1.000817 & 0.012041 & 0.012042 \\
\hline MML & -0.003358 & 0.413896 & 0.413908 & 1.000816 & 0.010877 & 0.010878 \\
\hline LAD & -0.001238 & 0.494956 & 0.494957 & 1.000694 & 0.013322 & 0.013322 \\
\hline WIN10 & -0.003894 & 0.459236 & 0.459251 & 1.000988 & 0.012092 & 0.012093 \\
\hline WIN20 & -0.001129 & 0.385763 & 0.385764 & 1.000446 & 0.010191 & 0.010191 \\
\hline TLS & -0.002565 & 0.445692 & 0.445699 & 1.000634 & 0.011855 & 0.011855 \\
\hline Theil & -0.002769 & 0.413026 & 0.413033 & 1.000909 & 0.010785 & 0.010786 \\
\hline Wtd.Theil & -0.000713 & 0.407067 & 0.407068 & 1.000667 & 0.010531 & 0.010531 \\
\hline
\end{tabular}

\begin{tabular}{|c|c|c|c|c|c|c|}
\hline \multicolumn{7}{|c|}{$P=3.0$} \\
\hline OLS & -0.002395 & 0.459847 & 0.459853 & 1.000911 & 0.012078 & 0.012079 \\
\hline MML & -0.001450 & 0.410860 & 0.410862 & 1.000782 & 0.010912 & 0.010913 \\
\hline LAD & 0.003457 & 0.556958 & 0.556970 & 0.999881 & 0.015020 & 0.015020 \\
\hline WIN10 & 0.002749 & 0.475428 & 0.475435 & 0.999938 & 0.012637 & 0.012637 \\
\hline WIN20 & 0.001543 & 0.415174 & 0.415177 & 1.000308 & 0.010967 & 0.010968 \\
\hline TLS & -0.002892 & 0.485833 & 0.485841 & 1.000915 & 0.012907 & 0.012908 \\
\hline Theil & 0.000275 & 0.448417 & 0.448417 & 1.000647 & 0.011503 & 0.011503 \\
\hline Wtd.Theil & 0.000458 & 0.438228 & 0.438228 & 1.000618 & 0.011210 & 0.011210 \\
\hline \multicolumn{7}{|c|}{$P=3.5$} \\
\hline OLS & -0.013050 & 0.470511 & 0.470681 & 1.000804 & 0.012082 & 0.012082 \\
\hline MML & -0.010891 & 0.434622 & 0.434741 & 1.000796 & 0.011308 & 0.011309 \\
\hline LAD & -0.012993 & 0.594436 & 0.594605 & 1.001073 & 0.016032 & 0.016034 \\
\hline WIN10 & -0.014704 & 0.510295 & 0.510512 & 1.001517 & 0.013519 & 0.013521 \\
\hline WIN20 & -0.010134 & 0.446861 & 0.446964 & 1.000764 & 0.011649 & 0.011650 \\
\hline TLS & -0.009950 & 0.524629 & 0.524728 & 1.000705 & 0.013743 & 0.013743 \\
\hline Theil & -0.009799 & 0.472920 & 0.473016 & 1.000470 & 0.011964 & 0.011964 \\
\hline Wtd.Theil & -0.009878 & 0.470252 & 0.470350 & 1.000552 & 0.011806 & 0.011806 \\
\hline \multicolumn{7}{|c|}{$P=5.0$} \\
\hline OLS & 0.006726 & 0.473619 & 0.473664 & 0.999226 & 0.012242 & 0.012243 \\
\hline MML & 0.006238 & 0.459306 & 0.459345 & 0.999366 & 0.011917 & 0.011917 \\
\hline LAD & 0.005333 & 0.653941 & 0.653969 & 0.999511 & 0.017332 & 0.017332 \\
\hline WIN10 & 0.004859 & 0.542576 & 0.542600 & 0.999847 & 0.014320 & 0.014320 \\
\hline WIN20 & 0.006534 & 0.482789 & 0.482832 & 0.999342 & 0.012526 & 0.012526 \\
\hline TLS & 0.005403 & 0.587715 & 0.587744 & 0.999960 & 0.015314 & 0.015314 \\
\hline Theil & 0.005450 & 0.523069 & 0.523098 & 0.999733 & 0.013058 & 0.013058 \\
\hline Wtd.Theil & 0.007827 & 0.507404 & 0.507465 & 0.999458 & 0.012595 & 0.012596 \\
\hline
\end{tabular}


Table 1 (continued): Means, Variances and MSE's for the estimators $\hat{\beta}_{0}$ and $\hat{\beta}_{1}, n=20$

\begin{tabular}{|c|c|c|c|c|c|c|}
\hline \multirow{2}{*}{$\begin{array}{r}m \\
\text { Method }\end{array}$} & \multicolumn{3}{|c|}{$\hat{\beta}_{0}$} & \multicolumn{3}{|c|}{$\hat{\beta}_{1}$} \\
\hline & Mean & Variance & MSE & Mean & Variance & MSE \\
\hline \multicolumn{7}{|c|}{$\mathrm{p}=2.0$} \\
\hline$\overline{\text { OLS }}$ & -0.002366 & 0.214414 & 0.214420 & 1.000324 & 0.001462 & 0.001463 \\
\hline MML & -0.001976 & 0.141376 & 0.141380 & 1.000244 & 0.000964 & 0.000964 \\
\hline LAD & -0.016728 & 0.152118 & 0.152398 & 1.001465 & 0.001097 & 0.001099 \\
\hline WIN10 & -0.000748 & 0.168078 & 0.168079 & 1.000103 & 0.001165 & 0.001165 \\
\hline WIN2 0 & -0.000829 & 0.128047 & 0.128048 & 1.000164 & 0.000879 & 0.000879 \\
\hline TLS & -0.000038 & 0.144824 & 0.144824 & 1.000100 & 0.001000 & 0.001000 \\
\hline Theil & 0.007148 & 0.132135 & 0.132187 & 0.999243 & 0.000896 & 0.000897 \\
\hline Wtd.Theil & -0.000949 & 0.130729 & 0.130730 & 1.000045 & 0.000880 & 0.000880 \\
\hline
\end{tabular}

\begin{tabular}{|c|c|c|c|c|c|c|}
\hline \multicolumn{7}{|c|}{$\mathrm{P}=2.5$} \\
\hline OLS & -0.004576 & 0.210169 & 0.210190 & 1.000161 & 0.001458 & 0.001458 \\
\hline MML & -0.005110 & 0.173648 & 0.173674 & 1.000131 & 0.001211 & 0.001211 \\
\hline LAD & -0.024790 & 0.207893 & 0.208508 & 1.001937 & 0.001483 & 0.001487 \\
\hline WIN10 & 0.000021 & 0.205904 & 0.205904 & 0.999652 & 0.001469 & 0.001469 \\
\hline WIN20 & -0.006372 & 0.161651 & 0.161691 & 1.000210 & 0.001144 & 0.001144 \\
\hline TLS & -0.006068 & 0.186094 & 0.186131 & 1.000211 & 0.001325 & 0.001325 \\
\hline Theil & 0.005634 & 0.173694 & 0.173725 & 0.999042 & 0.001185 & 0.001186 \\
\hline Wtd.Theil & -0.005509 & 0.171549 & 0.171580 & 1.000126 & 0.001166 & 0.001167 \\
\hline \multicolumn{7}{|c|}{$P=3.0$} \\
\hline OLS & -0.000997 & 0.217897 & 0.217898 & 1.000303 & 0.001517 & 0.001518 \\
\hline MML & -0.001199 & 0.190935 & 0.190936 & 1.000301 & 0.001320 & 0.001320 \\
\hline LAD & -0.015553 & 0.236484 & 0.236726 & 1.001847 & 0.001681 & 0.001684 \\
\hline WIN10 & -0.001128 & 0.227378 & 0.227379 & 1.000144 & 0.001614 & 0.001614 \\
\hline WIN20 & 0.000029 & 0.181401 & 0.181401 & 1.000151 & 0.001256 & 0.001256 \\
\hline TLS & 0.002355 & 0.211460 & 0.211466 & 1.000057 & 0.001474 & 0.001474 \\
\hline Theil & 0.014359 & 0.195260 & 0.195466 & 0.999013 & 0.001304 & 0.001305 \\
\hline Wtd.Theil & 0.001850 & 0.192893 & 0.192896 & 1.000188 & 0.001278 & 0.001278 \\
\hline \multicolumn{7}{|c|}{$P=3.5$} \\
\hline OLS & -0.005599 & 0.215732 & 0.215764 & 1.001062 & 0.001529 & 0.001530 \\
\hline MML & -0.002278 & 0.193426 & 0.193431 & 1.000902 & 0.001370 & 0.001371 \\
\hline LAD & -0.019423 & 0.262883 & 0.263260 & 1.002378 & 0.001877 & 0.001882 \\
\hline WIN10 & -0.002735 & 0.242673 & 0.242680 & 1.000908 & 0.001750 & 0.001751 \\
\hline WIN20 & -0.001386 & 0.195807 & 0.195809 & 1.000829 & 0.001384 & 0.001385 \\
\hline TLS & 0.003151 & 0.232698 & 0.232707 & 1.000321 & 0.001637 & 0.001637 \\
\hline Theil & 0.008258 & 0.211309 & 0.211377 & 0.999694 & 0.001439 & 0.001439 \\
\hline Wtd. Theil & -0.003741 & 0.209351 & 0.209365 & 1.000870 & 0.001413 & 0.001414 \\
\hline \multicolumn{7}{|c|}{$P=5.0$} \\
\hline OLS & -0.001472 & 0.206327 & 0.206329 & 1.000286 & 0.001458 & 0.001458 \\
\hline MML & -0.001661 & 0.196991 & 0.196994 & 1.000312 & 0.001395 & 0.001395 \\
\hline LAD & -0.019671 & 0.282823 & 0.283210 & 1.002131 & 0.002007 & 0.002011 \\
\hline WIN10 & 0.002690 & 0.250279 & 0.250286 & 0.999782 & 0.001833 & 0.001833 \\
\hline WIN20 & -0.002567 & 0.202167 & 0.202173 & 1.000406 & 0.001418 & 0.001419 \\
\hline TLS & -0.003974 & 0.243164 & 0.243180 & 1.000674 & 0.001704 & 0.001704 \\
\hline Theil & 0.013557 & 0.220453 & 0.220637 & 0.999055 & 0.001461 & 0.001462 \\
\hline Wtd.Theil & 0.001284 & 0.217649 & 0.217651 & 1.000161 & 0.001438 & 0.001438 \\
\hline
\end{tabular}




\section{MUTAN \& ȘENOĞLU}

Table 1 (continued): Means, Variances and MSE's for the estimators $\hat{\beta}_{0}$ and $\hat{\beta}_{1}, n=50$

\begin{tabular}{|c|c|c|c|c|c|c|}
\hline \multirow[b]{2}{*}{ Method } & \multicolumn{3}{|c|}{$\hat{\beta}_{0}$} & \multicolumn{3}{|c|}{$\hat{\beta}_{1}$} \\
\hline & Mean & Variance & MSE & Mean & Variance & MSE \\
\hline \multicolumn{7}{|c|}{$\mathrm{p}=2.0$} \\
\hline OLS & -0.000594 & 0.084085 & 0.084085 & 1.000087 & 0.000104 & 0.000104 \\
\hline MML & 0.001371 & 0.047691 & 0.047692 & 1.000004 & 0.000055 & 0.000055 \\
\hline LAD & 0.000378 & 0.052987 & 0.052987 & 0.999985 & 0.000063 & 0.000063 \\
\hline WIN10 & 0.006258 & 0.065587 & 0.065626 & 0.999828 & 0.000079 & 0.000079 \\
\hline WIN20 & 0.000867 & 0.046586 & 0.046586 & 1.000034 & 0.000055 & 0.000055 \\
\hline TLS & 0.001880 & 0.050630 & 0.050634 & 1.000005 & 0.000060 & 0.000060 \\
\hline Theil & -0.000014 & 0.047390 & 0.047390 & 1.000006 & 0.000054 & 0.000054 \\
\hline Wtd.Theil & -0.000386 & 0.047201 & 0.047202 & 1.000025 & 0.000053 & 0.000053 \\
\hline
\end{tabular}

\begin{tabular}{|c|c|c|c|c|c|c|}
\hline \multicolumn{7}{|c|}{$\mathrm{P}=2.5$} \\
\hline OLS & 0.002424 & 0.086628 & 0.086634 & 0.999785 & 0.000099 & 0.000099 \\
\hline MML & -0.000641 & 0.066412 & 0.066413 & 0.999911 & 0.000076 & 0.000076 \\
\hline LAD & 0.001515 & 0.080364 & 0.080366 & 0.999884 & 0.000094 & 0.000094 \\
\hline WIN10 & 0.004181 & 0.091114 & 0.091131 & 0.999756 & 0.000108 & 0.000108 \\
\hline WIN20 & -0.000303 & 0.064850 & 0.064850 & 0.999878 & 0.000075 & 0.000075 \\
\hline TLS & -0.004784 & 0.076472 & 0.076495 & 1.000056 & 0.000087 & 0.000087 \\
\hline Theil & 0.002601 & 0.068287 & 0.068294 & 0.999896 & 0.000075 & 0.000075 \\
\hline Wtd.Theil & 0.002145 & 0.068267 & 0.068272 & 0.999915 & 0.000075 & 0.000075 \\
\hline \multicolumn{7}{|c|}{$\mathrm{P}=3.0$} \\
\hline OLS & -0.012133 & 0.085280 & 0.085428 & 1.000378 & 0.000100 & 0.000100 \\
\hline MML & -0.011707 & 0.073272 & 0.073409 & 1.000390 & 0.000085 & 0.000085 \\
\hline LAD & -0.012364 & 0.089730 & 0.089883 & 1.000416 & 0.000106 & 0.000106 \\
\hline WIN10 & -0.007459 & 0.096523 & 0.096579 & 1.000233 & 0.000115 & 0.000115 \\
\hline WIN20 & -0.009552 & 0.071668 & 0.071759 & 1.000327 & 0.000084 & 0.000084 \\
\hline TLS & -0.010372 & 0.078219 & 0.078326 & 1.000291 & 0.000094 & 0.000094 \\
\hline Theil & -0.009797 & 0.075452 & 0.075548 & 1.000351 & 0.000084 & 0.000084 \\
\hline Wtd.Theil & -0.009190 & 0.074861 & 0.074945 & 1.000330 & 0.000083 & 0.000083 \\
\hline \multicolumn{7}{|c|}{$P=3.5$} \\
\hline OLS & -0.013384 & 0.081143 & 0.081322 & 1.000466 & 0.000093 & 0.000093 \\
\hline MML & -0.012900 & 0.070895 & 0.071062 & 1.000445 & 0.000082 & 0.000082 \\
\hline LAD & -0.009534 & 0.092041 & 0.092131 & 1.000356 & 0.000108 & 0.000108 \\
\hline WIN10 & -0.012675 & 0.089156 & 0.089317 & 1.000384 & 0.000108 & 0.000108 \\
\hline WIN2 0 & -0.012857 & 0.069653 & 0.069818 & 1.000447 & 0.000081 & 0.000081 \\
\hline TLS & -0.012912 & 0.079559 & 0.079725 & 1.000442 & 0.000093 & 0.000093 \\
\hline Theil & -0.012624 & 0.077350 & 0.077510 & 1.000469 & 0.000083 & 0.000083 \\
\hline Wtd.Theil & -0.012442 & 0.076734 & 0.076889 & 1.000476 & 0.000082 & 0.000082 \\
\hline \multicolumn{7}{|c|}{$\mathrm{P}=5.0$} \\
\hline OLS & 0.000349 & 0.080924 & 0.080924 & 1.000022 & 0.000093 & 0.000093 \\
\hline MML & -0.002554 & 0.075887 & 0.075893 & 1.000110 & 0.000088 & 0.000088 \\
\hline LAD & -0.004909 & 0.110364 & 0.110388 & 1.000214 & 0.000129 & 0.000129 \\
\hline WIN10 & 0.000915 & 0.100494 & 0.100495 & 1.000063 & 0.000122 & 0.000122 \\
\hline WIN20 & -0.001840 & 0.076396 & 0.076399 & 1.000070 & 0.000088 & 0.000088 \\
\hline TLS & -0.002449 & 0.093636 & 0.093642 & 1.000074 & 0.000108 & 0.000108 \\
\hline Theil & -0.003242 & 0.083709 & 0.083720 & 1.000146 & 0.000090 & 0.000090 \\
\hline Wtd.Theil & -0.002844 & 0.083042 & 0.083050 & 1.000120 & 0.000089 & 0.000089 \\
\hline
\end{tabular}




\section{LONG- TAILED SYMMETRIC DISTRIBUTION REGRESSION ESTIMATORS}

the shape parameter $p$ since OLS is the optimal method under normality and the $\operatorname{LTS}(p, \sigma)$ distribution approaches normal as $p \rightarrow \infty$. Results were not reproduced for the sake of brevity, however.

For the slope estimator $\hat{\beta}_{1}$ :

- For $p=2$ and 2.5, the performances of the WIN20 and WIN10 were the best at sample sizes 10 and 20 and Wtd.Theil and Theil provide the smallest MSE for the large sample sizes $(n=50)$.

- For $p=3.0$, WIN20 demonstrated the strongest performance with lowest MSE at all sample sizes except for $n=10$, in which case MML provides the smallest MSE.

- MML, WIN10 and Wtd.Theil were the preferred methods for $p=3.5$. When $p=5.0$, MML, WIN10 and WIN20 have the smallest MSE.

- The LAD and TLS slope estimators showed very poor performance with the largest MSE values at all sample sizes for all values of the shape parameter, $p$.

- The performance of the OLS slope estimator is similar to the OLS intercept estimator.

\section{Robustness}

In practice, a model is identified by Q-Q plots or goodness of fit tests. Neither of these methods, nor in fact any other method, identifies a model exactly or uniquely. In other words, the value of the shape parameter $p$ in $\operatorname{LTS}(p, \sigma)$ might be misspecified. Assume, for illustration, that the true distribution is the $\operatorname{LTS}(3.5, \sigma)$. To represent a large number of plausible alternatives, consider the following sample models:

- $\quad \operatorname{Model}(1): \operatorname{LTS}(2.0, \sigma)$

- $\operatorname{Model}(2): \operatorname{LTS}(5.0, \sigma)$

- Model (3): Outlier Model; (n-r) observations from $\operatorname{LTS}(3.5, \sigma)$ and $r$ observations from $\operatorname{LTS}(3.5,4 \sigma)$ where $r=[0.5+0.1 n]$

- Model (4): Mixture Model; 0.90LTS $(3.5, \sigma)$ $+0.10 \operatorname{LTS}(3.5,4 \sigma)$
- Model (5): Contamination Model; $0.90 \operatorname{LTS}(3.5, \sigma)+0.10 \operatorname{Normal}(0,4)$

The simulated means, variances and MSE of the regression estimators for the alternative models are shown in Table 2 . It should be noted that an estimator $\hat{\theta}$ of $\theta$ is called robust if it is fully efficient (or nearly so) for an assumed model but maintains high efficiencies for plausible alternatives to the assumed model. Based on the information in Table 2, the following conclusions are put forth for the intercept estimator $\hat{\beta}_{0}$ :

- WIN10 and WIN20 showed the strongest performance with lowest MSE for Models (1), (3), (4) and (5) at all sample sizes except for a sample of size 50 in Models (1) and (5) in which case the Wtd. Theil provides the smallest MSE.

- MML demonstrated the strongest performance with lowest MSE as compared to other methods in Model (2).

- OLS and LAD showed very poor estimator performance at all sample sizes with largest MSE values for Models (1), (3), (4), (5) and Model (2), respectively.

For the slope estimator $\hat{\beta}_{1}$ :

- WIN10 and WIN20 provided the smallest MSE for Models (1), (3), (4) and (5) at sample sizes 10 and 20 , however, for the sample size $n=50$, the Wtd. Theil's slope estimator had the strongest efficiency.

- The highest performance for Model (2), similar to intercept estimator $\hat{\beta}_{0}$, is achieved by MML.

- OLS and LAD have the highest MSE values for Models (1), (3), (4), (5) and Model (2), respectively. Therefore, they are not preferred estimators under these sample models.

\section{Conclusion}

The OLS estimation procedure provides good results when the error terms have a normal distribution. However, in real life, it is nearly impossible to find a data set that satisfies all of 


\section{MUTAN \& ȘENOĞLU}

Table 2: Means, Variances and MSE's for the sample models (1)-(5), $n=10$

\begin{tabular}{|c|c|c|c|c|c|c|}
\hline \multirow[b]{2}{*}{ Method } & \multicolumn{3}{|c|}{$\hat{\beta}_{0}$} & \multicolumn{3}{|c|}{$\hat{\beta}_{1}$} \\
\hline & Mean & Variance & MSE & Mean & Variance & MSE \\
\hline & \multicolumn{6}{|c|}{ Model (1) } \\
\hline OLS & -0.012290 & 0.485174 & 0.485325 & 1.001940 & 0.012996 & 0.013000 \\
\hline MML & -0.010016 & 0.352918 & 0.353018 & 1.001675 & 0.009657 & 0.009660 \\
\hline LAD & -0.009981 & 0.357653 & 0.357753 & 1.001655 & 0.009603 & 0.009605 \\
\hline WIN10 & -0.007079 & 0.365626 & 0.365676 & 1.001175 & 0.009806 & 0.009807 \\
\hline WIN20 & -0.010102 & 0.317492 & 0.317594 & 1.001656 & 0.007995 & 0.007998 \\
\hline TLS & -0.009358 & 0.325208 & 0.325295 & 1.001784 & 0.008635 & 0.008638 \\
\hline Theil & -0.010226 & 0.307593 & 0.307697 & 1.001484 & 0.008033 & 0.008035 \\
\hline \multirow[t]{2}{*}{ Wtd.Theil } & -0.012949 & 0.308182 & 0.308350 & 1.001986 & 0.008008 & 0.008012 \\
\hline & \multicolumn{6}{|c|}{ Model (2) } \\
\hline OLS & -0.006355 & 0.470296 & 0.470337 & 1.000850 & 0.012108 & 0.012109 \\
\hline MML & -0.006313 & 0.456893 & 0.456933 & 1.000915 & 0.011789 & 0.011790 \\
\hline LAD & -0.008034 & 0.656990 & 0.657055 & 1.001427 & 0.017477 & 0.017479 \\
\hline WIN10 & -0.008389 & 0.546347 & 0.546417 & 1.001590 & 0.014378 & 0.014380 \\
\hline WIN2 0 & -0.006451 & 0.480393 & 0.480435 & 1.001023 & 0.012422 & 0.012423 \\
\hline TLS & -0.005099 & 0.577213 & 0.577239 & 1.000909 & 0.015085 & 0.015086 \\
\hline Theil & -0.005327 & 0.520019 & 0.520047 & 1.000805 & 0.012966 & 0.012966 \\
\hline \multirow[t]{2}{*}{ Wtd.Theil } & -0.006527 & 0.507479 & 0.507522 & 1.001039 & 0.012562 & 0.012563 \\
\hline & \multicolumn{6}{|c|}{ Model (3) } \\
\hline OLS & 0.012384 & 1.223769 & 1.223923 & 0.998354 & 0.032164 & 0.032167 \\
\hline MML & 0.009457 & 0.753716 & 0.753806 & 0.998816 & 0.020260 & 0.020262 \\
\hline LAD & 0.016420 & 0.751355 & 0.751625 & 0.997478 & 0.019980 & 0.019987 \\
\hline WIN10 & -0.010434 & 0.754763 & 0.754872 & 1.000511 & 0.019574 & 0.019574 \\
\hline WIN2 0 & 0.008255 & 0.630553 & 0.630621 & 0.998781 & 0.016398 & 0.016400 \\
\hline TLS & 0.012560 & 0.667084 & 0.667242 & 0.998366 & 0.017401 & 0.017404 \\
\hline Theil & 0.007114 & 0.660818 & 0.660869 & 0.999191 & 0.016871 & 0.016872 \\
\hline Wtd.Theil & 0.006276 & 0.658813 & 0.658853 & 0.999105 & 0.016838 & 0.016839 \\
\hline
\end{tabular}

Model (4)

\begin{tabular}{lllllll}
\hline OLS & -0.015771 & 1.169783 & 1.170031 & 1.003291 & 0.030152 & 0.030163 \\
MML & -0.015086 & 0.776937 & 0.777164 & 1.002934 & 0.020509 & 0.020518 \\
LAD & -0.022904 & 0.798735 & 0.799260 & 1.003815 & 0.021329 & 0.021343 \\
WIN10 & -0.026484 & 0.830451 & 0.831153 & 1.003516 & 0.021298 & 0.021310 \\
WIN20 & -0.013370 & 0.661862 & 0.662040 & 1.002650 & 0.017077 & 0.017084 \\
TLS & -0.011041 & 0.710763 & 0.710885 & 1.002151 & 0.018798 & 0.018803 \\
Theil & -0.016685 & 0.694106 & 0.694385 & 1.002835 & 0.017787 & 0.017795 \\
Wtd.Theil & -0.015797 & 0.690942 & 0.691192 & 1.002849 & 0.017729 & 0.017737 \\
\hline
\end{tabular}

Model (5)

\begin{tabular}{lrlllll}
\hline OLS & -0.004107 & 1.179549 & 1.179566 & 1.001699 & 0.030212 & 0.030215 \\
MML & -0.001795 & 0.797778 & 0.797782 & 1.001125 & 0.021203 & 0.021204 \\
LAD & 0.004313 & 0.797272 & 0.797291 & 0.999694 & 0.021461 & 0.021461 \\
WIN10 & -0.011044 & 0.839572 & 0.839694 & 1.001791 & 0.022213 & 0.022217 \\
WIN20 & 0.000062 & 0.684177 & 0.684177 & 1.000728 & 0.017888 & 0.017889 \\
TLS & 0.002536 & 0.742882 & 0.742889 & 1.000399 & 0.019719 & 0.019719 \\
Theil & -0.000683 & 0.701909 & 0.701910 & 1.000896 & 0.018376 & 0.018377 \\
Wtd.Theil & -0.001727 & 0.715698 & 0.715701 & 1.000978 & 0.018841 & 0.018842
\end{tabular}


LONG- TAILED SYMMETRIC DISTRIBUTION REGRESSION ESTIMATORS

Table 2 (continued): Means, Variances and MSE's for the sample models (1)-(5), $n=20$

\begin{tabular}{|c|c|c|c|c|c|c|}
\hline \multirow[b]{2}{*}{ Method } & \multicolumn{3}{|c|}{$\hat{\beta}_{0}$} & \multicolumn{3}{|c|}{$\hat{\beta}_{1}$} \\
\hline & Mean & Variance & MSE & Mean & Variance & MSE \\
\hline & \multicolumn{6}{|c|}{ Model (1) } \\
\hline$\overline{\text { OLS }}$ & -0.003752 & 0.222670 & 0.222685 & 0.999951 & 0.001546 & 0.001546 \\
\hline MML & -0.004145 & 0.138954 & 0.138971 & 1.000165 & 0.000966 & 0.000966 \\
\hline LAD & -0.014743 & 0.152306 & 0.152524 & 1.001444 & 0.001072 & 0.001074 \\
\hline WIN10 & -0.004923 & 0.163155 & 0.163179 & 1.000060 & 0.001149 & 0.001149 \\
\hline WIN2 0 & -0.001735 & 0.123830 & 0.123833 & 1.000051 & 0.000863 & 0.000863 \\
\hline TLS & -0.002840 & 0.142264 & 0.142272 & 1.000216 & 0.000988 & 0.000988 \\
\hline Theil & 0.011090 & 0.129912 & 0.130035 & 0.998996 & 0.000873 & 0.000874 \\
\hline Wtd. Theil & 0.001468 & 0.128770 & 0.128772 & 0.999909 & 0.000861 & 0.000861 \\
\hline
\end{tabular}

\begin{tabular}{|c|c|c|c|c|c|c|}
\hline & & & Model & (2) & & \\
\hline OLS & -0.009421 & 0.220500 & 0.220589 & 1.000323 & 0.001527 & 0.001527 \\
\hline MML & -0.007871 & 0.208822 & 0.208884 & 1.000299 & 0.001453 & 0.001453 \\
\hline LAD & -0.015340 & 0.296896 & 0.297132 & 1.001461 & 0.002084 & 0.002086 \\
\hline WIN10 & -0.008323 & 0.263561 & 0.263631 & 1.000316 & 0.001861 & 0.001861 \\
\hline WIN2 0 & -0.006477 & 0.212390 & 0.212432 & 1.000258 & 0.001475 & 0.001475 \\
\hline TLS & -0.000358 & 0.260313 & 0.260313 & 0.999871 & 0.001816 & 0.001816 \\
\hline Theil & 0.010322 & 0.231483 & 0.231589 & 0.998944 & 0.001514 & 0.001515 \\
\hline Wtd.Theil & -0.002871 & 0.228255 & 0.228263 & 1.000186 & 0.001491 & 0.001491 \\
\hline
\end{tabular}

\begin{tabular}{|c|c|c|c|c|c|c|}
\hline OLS & 0.008763 & 0.534048 & 0.534125 & 0.998650 & 0.003708 & 0.003710 \\
\hline MML & 0.009852 & 0.271805 & 0.271903 & 0.998716 & 0.001954 & 0.001955 \\
\hline LAD & -0.004580 & 0.312706 & 0.312727 & 0.999984 & 0.002225 & 0.002225 \\
\hline WIN10 & 0.007319 & 0.356939 & 0.356993 & 0.998841 & 0.002524 & 0.002525 \\
\hline WIN20 & 0.010996 & 0.254113 & 0.254234 & 0.998615 & 0.001813 & 0.001815 \\
\hline TLS & 0.012679 & 0.292134 & 0.292295 & 0.998599 & 0.002067 & 0.002069 \\
\hline Theil & 0.025097 & 0.270968 & 0.271598 & 0.997220 & 0.001856 & 0.001864 \\
\hline Wtd.Theil & 0.010753 & 0.268535 & 0.268651 & 0.998603 & 0.001824 & 0.001826 \\
\hline
\end{tabular}

\begin{tabular}{|c|c|c|c|c|c|c|}
\hline & & & Model & (4) & & \\
\hline OLS & -0.011834 & 0.530361 & 0.530501 & 1.000266 & 0.003641 & 0.003641 \\
\hline MML & -0.007635 & 0.285413 & 0.285471 & 1.000330 & 0.002019 & 0.002019 \\
\hline LAD & -0.021156 & 0.320834 & 0.321282 & 1.001696 & 0.002262 & 0.002265 \\
\hline WIN10 & -0.002971 & 0.383144 & 0.383153 & 0.999619 & 0.002664 & 0.002664 \\
\hline WIN2 0 & -0.004989 & 0.263167 & 0.263192 & 1.000165 & 0.001853 & 0.001853 \\
\hline TLS & -0.002033 & 0.301227 & 0.301231 & 0.999793 & 0.002084 & 0.002084 \\
\hline Theil & 0.007851 & 0.274877 & 0.274938 & 0.998851 & 0.001875 & 0.001876 \\
\hline Wtd. Theil & -0.005549 & 0.272119 & 0.272150 & 1.000128 & 0.001839 & 0.001839 \\
\hline & & & Model & (5) & & \\
\hline OLS & -0.014204 & 0.546967 & 0.547169 & 1.000832 & 0.003830 & 0.003830 \\
\hline MML & -0.007622 & 0.291418 & 0.291476 & 1.000401 & 0.002046 & 0.002046 \\
\hline LAD & -0.018763 & 0.323247 & 0.323599 & 1.001347 & 0.002247 & 0.002249 \\
\hline WIN10 & -0.012408 & 0.388890 & 0.389044 & 1.000889 & 0.002683 & 0.002684 \\
\hline WIN20 & -0.007292 & 0.271799 & 0.271852 & 1.000305 & 0.001893 & 0.001893 \\
\hline TLS & -0.000146 & 0.296508 & 0.296508 & 0.999684 & 0.002040 & 0.002040 \\
\hline Theil & 0.006440 & 0.283805 & 0.283846 & 0.999057 & 0.001913 & 0.001914 \\
\hline Wtd.Theil & -0.007353 & 0.281584 & 0.281638 & 1.000388 & 0.001892 & 0.001892 \\
\hline
\end{tabular}




\section{MUTAN \& ȘENOĞLU}

Table 2 (continued): Means, Variances and MSE's for the sample models (1)-(5), $n=50$

\begin{tabular}{|c|c|c|c|c|c|c|}
\hline \multirow[b]{2}{*}{ Method } & \multicolumn{3}{|c|}{$\hat{\beta}_{0}$} & \multicolumn{3}{|c|}{$\hat{\beta}_{1}$} \\
\hline & Mean & Variance & MSE & Mean & Variance & MSE \\
\hline \multicolumn{7}{|c|}{ Model (1) } \\
\hline$\overline{\mathrm{OLS}}$ & -0.000805 & 0.074541 & 0.074542 & 0.999982 & 0.000084 & 0.000084 \\
\hline MML & -0.000114 & 0.044790 & 0.044790 & 0.999976 & 0.000050 & 0.000050 \\
\hline LAD & 0.004056 & 0.051563 & 0.051579 & 0.999809 & 0.000059 & 0.000059 \\
\hline WIN10 & -0.002538 & 0.065713 & 0.065719 & 1.000100 & 0.000077 & 0.000077 \\
\hline WIN20 & 0.000232 & 0.045412 & 0.045412 & 0.999965 & 0.000052 & 0.000052 \\
\hline TLS & 0.001835 & 0.048722 & 0.048726 & 0.999970 & 0.000055 & 0.000055 \\
\hline Theil & -0.000018 & 0.044688 & 0.044688 & 0.999963 & 0.000050 & 0.000050 \\
\hline Wtd.Theil & -0.000159 & 0.044719 & 0.044719 & 0.999970 & 0.000050 & 0.000050 \\
\hline \multicolumn{7}{|c|}{ Model (2) } \\
\hline OLS & -0.005070 & 0.082616 & 0.082642 & 1.000184 & 0.000095 & 0.000095 \\
\hline MML & -0.003343 & 0.078478 & 0.078489 & 1.000146 & 0.000091 & 0.000091 \\
\hline LAD & -0.004388 & 0.107137 & 0.107156 & 1.000242 & 0.000124 & 0.000124 \\
\hline WIN10 & -0.002386 & 0.102003 & 0.102008 & 1.000153 & 0.000125 & 0.000125 \\
\hline WIN2 0 & -0.002738 & 0.079004 & 0.079012 & 1.000119 & 0.000092 & 0.000092 \\
\hline TLS & -0.001691 & 0.099586 & 0.099589 & 1.000081 & 0.000116 & 0.000116 \\
\hline Theil & -0.001652 & 0.086823 & 0.086826 & 1.000123 & 0.000093 & 0.000093 \\
\hline Wtd.Theil & -0.001529 & 0.086498 & 0.086501 & 1.000126 & 0.000092 & 0.000092 \\
\hline
\end{tabular}

\begin{tabular}{|c|c|c|c|c|c|c|}
\hline OLS & 0.001170 & 0.218986 & 0.218987 & 1.000070 & 0.000247 & 0.000247 \\
\hline MML & 0.005980 & 0.138048 & 0.138083 & 0.999923 & 0.000149 & 0.000149 \\
\hline LAD & 0.007935 & 0.116472 & 0.116535 & 0.999940 & 0.000131 & 0.000131 \\
\hline WIN10 & 0.006277 & 0.158747 & 0.158786 & 0.999961 & 0.000176 & 0.000176 \\
\hline WIN2 0 & 0.007735 & 0.102137 & 0.102197 & 0.999891 & 0.000112 & 0.000112 \\
\hline TLS & 0.005534 & 0.118133 & 0.118164 & 1.000001 & 0.000130 & 0.000130 \\
\hline Theil & 0.008831 & 0.099889 & 0.099967 & 0.999887 & 0.000108 & 0.000109 \\
\hline Wtd.Theil & 0.009458 & 0.100008 & 0.100097 & 0.999849 & 0.000108 & 0.000108 \\
\hline
\end{tabular}

\begin{tabular}{|c|c|c|c|c|c|c|}
\hline & & & Model & (4) & & \\
\hline OLS & 0.007550 & 0.213060 & 0.213117 & 0.999828 & 0.000249 & 0.000249 \\
\hline MML & 0.008803 & 0.134974 & 0.135051 & 0.999741 & 0.000155 & 0.000155 \\
\hline LAD & 0.009354 & 0.118182 & 0.118269 & 0.999582 & 0.000142 & 0.000142 \\
\hline WIN10 & 0.014525 & 0.166463 & 0.166674 & 0.999435 & 0.000197 & 0.000197 \\
\hline WIN2 0 & 0.007484 & 0.104324 & 0.104380 & 0.999757 & 0.000123 & 0.000123 \\
\hline TLS & 0.003825 & 0.115579 & 0.115593 & 0.999892 & 0.000138 & 0.000138 \\
\hline Theil & 0.006978 & 0.103516 & 0.103565 & 0.999747 & 0.000119 & 0.000119 \\
\hline Wtd. Theil & 0.007271 & 0.103704 & 0.103757 & 0.999727 & 0.000118 & 0.000119 \\
\hline & & & Model & (5) & & \\
\hline OLS & 0.000823 & 0.213641 & 0.213642 & 1.000111 & 0.000251 & 0.0002 \\
\hline MML & 0.001214 & 0.139224 & 0.139226 & 1.000019 & 0.000158 & 0.000158 \\
\hline LAD & -0.006313 & 0.123031 & 0.123071 & 1.000148 & 0.000146 & 0.000146 \\
\hline WIN10 & 0.002004 & 0.175000 & 0.175004 & 1.000008 & 0.000198 & 0.000198 \\
\hline WIN2 0 & 0.000914 & 0.109873 & 0.109874 & 0.999948 & 0.000129 & 0.000129 \\
\hline TLS & 0.001631 & 0.116706 & 0.116709 & 0.999897 & 0.000135 & 0.000135 \\
\hline Theil & -0.000120 & 0.107528 & 0.107528 & 0.999936 & 0.000122 & 0.000122 \\
\hline Wtd.Theil & -0.000712 & 0.107393 & 0.107394 & 0.999947 & 0.000122 & 0.000122 \\
\hline
\end{tabular}




\section{LONG- TAILED SYMMETRIC DISTRIBUTION REGRESSION ESTIMATORS}

the normality assumptions, therefore, alternative regression methods are needed. In this study, efficiency and robustness properties of some prominent robust and nonparametric regression estimators have been compared via Monte Carlo simulation when the error terms come from long-tailed symmetric $\operatorname{LTS}(p, \sigma)$ distributions.

The methods giving the smallest MSE for various shape parameters and sample models were defined clearly for different sample sizes. If the distribution of error terms is $\operatorname{LTS}(p, \sigma)$ in a simple linear regression model, it is therefore suggested that the selection procedure for the most efficient and robust method of estimation should be accomplished according to the results given above.

\section{References}

Birkes, D., \& Dodge, Y. (1993). Alternative methods of regression. New York, NY: Wiley.

Geary, R. C. (1947). Testing for normality. Biometrika, 34, 209-242.

Huber, P. J. (1981). Robust statistics. NY: John Wiley.

Hussain, S. S., \& Sprent, P. (1983). Nonparametric regression. Journal of the Royal Statistical Society, A146, 182-191.

Jaeckel, L. A. (1972). Estimating regression coefficients by minimizing the dispersion of residuals. Annals of Mathematical Statistics, 43, 1449-1458.

Nevitt, T., \& Tam, H. P. (1998). A comparison of robust and nonparametric estimators under the simple linear regression model. Multiple Linear Regression Viewpoints, 25, 54-69.
Pearson, E. S. (1932). The analysis of variance in cases of nonnormal variation. Biometrika, 23, 114-133.

Rousseeuw, P. J., \& Leroy, A. M. (1987). Robust regression and outlier detection. New York, NY: Wiley.

Scholz, F.W. (1978). Weighted median regression estimates. The Annals of Statistics, 6(3), 603-609.

Sprent, P. (1993). Applied nonparametric statistical methods. NY: Chapman and Hall.

Şenoğlu, B. (2005). Robust $2^{k}$ factorial design with Weibull error distributions. Journal of Applied Statistics, 32(10), 1051-1066.

Şenoğlu, B. (2007). Estimating parameters in one-way analysis of covariance model with short-tailed symmetric error distributions. Journal of Computational and Applied Mathematics, 201, 275-283.

Tam, H. P. (1996). A review of nonparametric regression techniques. Paper presented at the annual meeting of the American Educational Research Association, New York.

Theil, H. (1950). A rank-invariant method of linear and polynomial regression analysis. Indagationes Mathematicae, 12, 85-91.

Tiku, M. L., Islam, M. Q., \& Selçuk, A. (2001). Non-normal regression II: Symmetric distributions. Communications in Statistics Theory and Methods, 30, 1021-1045.

Yale, C., \& Forsythe, A. B. (1976). Winsorized regression. Technometrics, 18, 291300 . 